\title{
Non-Antibiotic Compounds: The Activity of the NSAID Diclofenac on Bacteria- A Review
}

\author{
Agostinho Alves de Lima e Silva* and Priscila Martins Silva
}

Department of Microbiology and Parasitology, Biomedical Institute, Federal University of the State of Rio de Janeiro (UNIRIO), Frei Caneca St, no. 94, Rio de Janeiro, RJ, Brazil

*Corresponding author

\section{A B S T R A C T}

\section{Keywords \\ Non-antibiotics, Diclofenac, Anti- bacterial action, Anti-biofilm activity}

\section{Article Info}

Accepted:

04 November 2018

Available Online:

10 December 2018

\begin{abstract}
Bacterial multidrug resistanceis a phenomenon that has been growing with increasing speed worldwide. New mechanisms of resistance have been described in different bacterial pathogens, representing a threat to effective treatments of common infectious diseases with currently available drugs. The use of drugs known as "non-antibiotics are among the alternative approaches to the use of conventional antibiotics. This approach has been studied in order to counteract the global threat of multidrug resistance. This group of drugs includes various non-steroidal anti-inflammatory drugs (NSAIDs). The NSAID diclofenac has demonstrated broad-spectrum antimicrobial activity in vitro and in vivo. In addition, this drug has an synergistic antibacterial effect when combined with certain other drugs. It may also show anti-biofilm activity, and may inhibit or decrease the activity of certain virulence factors in some bacterial pathogens.
\end{abstract}

\section{Introduction}

In recent decades, due to the dramatic increase and global spread of bacterial resistance to a number of commonly used antibacterial agents, many studies have been directed at investigating drugs whose primary therapeutic purpose is not antimicrobial action.

Classic commonly used antimicrobials include antibiotics of natural originproduced by fungi and bacteria (e.g., penicillin $\mathrm{G}$ and streptomycin), semi-synthetic antibiotics (e.g., oxacillin and amoxicillin), and drugs produced entirely via chemical synthesis, such as quinolones and sulphonamides. However, studies have shown that certain other pharmacological classes of drugs - such as neuroleptics (Kristiansen, 1979), antihistamines (Dastidar et al., 1996), and non-steroidal anti-inflammatory drugs (NSAIDs) (Zimmermann and Curtis, 2017; Shah et al., 2018) - have a greater or lesser degree of broad-spectrum antibacterial activity. Kristiansen (1992) coined the term "non-antibiotics" for such drugs.

Among these "non-antibiotics", most studies have focused on NSAIDs, drugs that - in addition to anti-inflammatory action - have analgesic and antipyretic properties. These drugs are among the most widely used in the 
world. Their main mechanism of action involves the inhibition of cyclooxygenase, which leads to a decrease in the synthesis of prostaglandins (Dinarello, 2010).

The most commonly prescribed NSAIDs in clinical practice include drugs such as diclofenac, ibuprofen, indomethacin, and acetylsalicylic acid. Their antimicrobial action comprises bacterial isolates of different species, as well as fungi (Zimmermann and Curtis, 2017).

Diclofenac is the 2- (2,6-dichloranilino) phenylacetic acid. It can be supplied as either sodium or potassium salt, both with good solubility in solvents such as methanol and DMSO. However, most studies involving the action of diclofenac on bacteria have been conducted using its sodium form. This NSAID showed antimicrobial activity in vitro against different bacterial pathogens (Tables 1 and 2). In an interesting approach, Alqahtani et al., (2018) prepared chitosan nanoparticles loaded with diclofenac and demonstrated high activity of this cluster against $S$. aureus and $B$. subtilis, which depended on the molecular weight of chitosan and $\mathrm{pH}$.

The mechanism of action of diclofenac seems to reside mainly in the inhibition of DNA synthesis (Dastidar et al., 2000). Particularly in E. coli, some NSAIDs showed an ability to inhibit the DNA polymerase III $\beta$ subunit. The change of this subunit as a consequence of the binding of the NSAID molecule results in inhibition of DNA replication and repair(Yin et al., 2014). Besides that, the increase in the uptake of ethidium bromide in $S$. aureus cells exposed to diclofenac sodium has provided evidence that NSAIDs may also act by compromising cellular membrane integrity (El-Baky and El-Gendy, 2016).

The activity of diclofenac has been reported as bactericidal for Gram-positive and Gram- negative bacteria, in addition to mycobacteria (Dastidar et al., 2000; Dutta et al., 2007a, 2007b; Mazumdar et al., 2009). However, Perilli (2000) showed that the action of this drug on the growth of $S$. epidermidis was bacteriostatic, since subsequent subcultures restored normal growth rates of the isolates.

Riordan et al., (2011) described extensive changes in the transcriptome of methicillinresistant $S$. aureus (MRSA) strain COLwhen grown with subinhibitory concentrations of diclofenac. Changes in the expression of hundreds of genes were noted, including those associated with resistance to antimicrobials. Transcriptional alterations were measured using gene expression microarrays and realtime quantitative polymerase chain reactions (qPCR). It was further shown that diclofenac altered susceptibility to multiple antibiotics in a strain-dependent manner. Susceptibility increased for ciprofloxacin, ofloxacin, and norfloxacin, decreased for oxacillin and vancomycin, and did not change for tetracycline or chloramphenicol.

In $E$. coli isolates of urinary tract infections, diclofenac exhibited pronounced antibacterial activity; sequential exposure to high concentrations of the drug resulted in the emergence of mutants with noticeable reduction in the minimum inhibitory concentration (MIC) values ofthe antibiotics. In addition, agarose gel electrophoresis showed the absence of any specific band of plasmid in the mutant, in contrast to what was observed in the control isolate (Mazumdar et al., 2006).

Studies have shown that the broad-spectrum antibacterial effects promoted by NSAIDs are not restricted to the results obtained in vitro. Administration of diclofenac to mice at doses of 1.5 and $3.0 \mu \mathrm{g} / \mathrm{g}$ of body weight could significantly protect these animals from death after experimental infection with $S$. enterica 
ser. typhimurium (Annaduraiet al., 1998). Identical results were obtained by Dutta et al., (2007a).

Diclofenac was also able to act in experimental infections caused by $M$. tuberculosis and Listeria monocytogenes. The inoculation of $M$. tuberculosis in mice followed by treatment with diclofenac resulted in fewer lesions and lower bacillary loads than were found in control animals (Dutta et al., 2004a). A similar finding was reported by Dutta et al., (2004b), with a marked decrease in the lesions of organs of mice treated with diclofenac after infection with $M$. tuberculosis.

Dutta et al., (2008b) also showed that diclofenac provided protection to $\mathrm{BALB} / \mathrm{c}$ mice challenged orally with $L$. monocytogenes. Significant reduction of bacterial counts in the liver and spleen, a 10fold decrease in the number and size of necrotic foci, and the positive regulation of inflammatory cytokine expression were observed in this study.

\section{Synergy with antimicrobial drugs}

Besides the direct antimicrobial action of NSAIDs, their association with antibiotics can result in inhibitory or bactericidal synergistic activity against bacterial pathogens. Annadurai et al., (2002) found clear in vitro synergism between diclofenac and streptomycin for different species of Grampositive and Gram-negative bacteria. In vivo, administration of both drugs in mice previously infected with Salmonella resulted in notable reductions in the number of pathogens found in blood, liver, and spleen samples.

Using a disk diffusion test, Dutta et al., (2007a) found that combining diclofenac with streptomycin resulted in significant increases in the zones of inhibition of E. coli ATCC 25922.Likewise, as reported by Annadurai et al., (2002), the association of these drugs resulted in a significant reduction in Salmonella counts in the organs of infected mice. Heightened inhibition was also shown in vitro for M. smegmatis (Dutta et al., 2004.b), and this synergism was later corroborated in vivo: mice intravenously infected with $M$. tuberculosis and then treated with these drugs showed a notable decrease in the count of bacteria recovered from the lungs and spleen, compared with mice receiving streptomycin alone (Dutta et al., 2007b).

A synergistic effect was still observed for Listeria monocytogenes in invitro tests using diclofenacin association with gentamicin (Dutta, Mazumdar and Park, 2009). On the other hand, when Shepherd et al., (1998) compared the efficacy and safety of ocular drops containing a combination of diclofenac and gentamicin and eyedrops containing only gentamicin - both administered during the postoperative management of patients undergoing cataract surgery and lens implantation - they concluded that the combined drugs were more effective in controlling inflammation.

\section{Diclofenac and biofilms}

In addition to investigating their potential for antibacterial activity, researchers have analyzed the effects of NSAIDs on biofilms and other factors linked to bacterial virulence. Biofilms are complex multicellular communities of microorganisms that proliferate while surrounded by a polymeric matrix, conferring an antimicrobial survival capacity and protection against the immune defense mechanisms of the host (Otto, 2013)

The mechanism by which NSAIDs impact biofilm formation is not completely understood. The reduction of components that 
may form part of the biofilm matrix (such as extracellular polysaccharides, teichoic acids and proteins), alteration of cell surface hydrophobicity, or inhibition of components of the quorum-sensing system are factors that must be considered (Oprea and Moga, 2015).

In most studies of drugs with potential for anti-biofilm activity, the objective is to evaluate the effect on preformed biofilms. This approach depends on the drug's ability to diffuse through the biofilm to exert its effect directly on the pathogen, or to act by disintegrating the biofilm so that the exposed pathogen becomes an easier target for antimicrobials. In other studies, however, the investigative focus is on the drug's ability to act during the stages during which planktonic cells adhere to a surface, in order to inhibit the early stages of biofilm formation.

According to Hegazy (2016), subinhibitory concentrations of diclofenac resulted in marked inhibition of biofilm formation produced by $P$. mirabilis (90\% in $1 / 2$ MIC), and decreased the value of the MBIC (minimum biofilm inhibitory concentration) for the different antibiotics tested. Primary bacterial adhesion was not significantly affected, indicating that effective drug activity occurred during the later stages of biofilm formation. As reported by Hegazy (2016), this may be the result of diclofenac's effect on the intercellular signaling system known as quorum sensing. This system is based on cell density and regulates functions that contribute to the virulence of many bacterial pathogens, including biofilm production (Waters and Bassler, 2005).

El-Baky and El-Gendy (2016) also reported that different NSAIDs produced a noticeable inhibitory effect on both biofilm formation and preformed $S$. aureus biofilm. While meloxicam was identified as the NSAID with the greatest capacity to inhibit biofilm formation, diclofenac was found to have the greatest ability to degrade preformed biofilm. Both effects were higher than those observed for the antimicrobial levofloxacin. This study further revealed that NSAIDs negatively regulated icaA gene expression. This gene is one of the components of the icaADBC operon, which encodes the production of PIA (polysaccharide intercellular adhesin), the main component of the extracellular matrix of the polysaccharide biofilm in Staphylococcus (Cramton et al., 1999).

The effect of NSAIDs on biofilm may vary according to the particular characteristics of strains of a species. Perilli (2000) investigated two slime-positive isolates of $S$. epidermidis from catheter-associated infections: one negative and one positive for a slimeassociated antigen (SAA). In the SAAnegative strain, short-term treatments with diclofenac significantly reduced biofilm production in microtiter plates; the SAApositive strain was not affected. After the colonization and treatment of each strain on a contact lens surface, scanning electron microscopy confirmed that the drug promoted complete disorganization of the biofilm structure in the SAA-negative strain. The drug's lack of effect on the SAA-positive strain was attributed to the differences between the composition of its slime material and that of the SAA-negative isolate.

Reśliński, Dąbrowiecki andGłowacka(2015) showed that diclofenac - in concentration equal to that reached in human serum limited the formation of strong biofilm by clinical isolates of $S$. aureus and E. coli grown on the surface of polypropylene mesh, which is commonly used in hernia surgery. On the other hand, the percentage of strains which formed weak biofilm increased from $1.4 \%$ (control regimen) to $10.0 \%$ (diclofenac). In our research, we have also observed diclofenac's effect on the induction of weak 
biofilm production in some $S$. aureus isolates (work in progress - Figure 1).

In a clinical strain of $P$. aeruginosa that produced a strong biofilm, diclofenac (1/4 of MIC) reduced biofilm formation to about $60 \%$ of that observed in the control (Abbas 2015). However, an earlier study showed that the activity of this drug on preformed biofilms by clinical strains of $P$. aeruginosa was only moderate.

\section{The effects of combining diclofenac with other drugs on biofilm production}

In some investigations, the focus was on assessing whether NSAIDs - combined with each other or associated with other substances - affect biofilm formation, or alter the density of preformed biofilms. Baldiris et al., (2016) reported that the combination of diclofenac and ibuprofen in subinhibitory concentrations produced a significant reduction in biofilm formation in clinical isolates of $K$. pneumoniae and E. coli, both previously characterized as producers of strong biofilms. The association of diclofenac (and also ibuprofen) with $\mathrm{N}$-acetyl cysteine resulted in an marked disruptive effect on mature biofilms formed by some Gram-negative bacteria and S. aureus (Mohsen et al., 2015).

Increased anti-biofilm effect was also observed in the combination of diclofenac or ibuprofen with calcium paste $(\mathrm{CH})$. Calcium hydroxide is widely used in dentistry because of its antimicrobial and biological effects. Combining these NSAIDs with $\mathrm{CH}$ did not interfere in the paste's $\mathrm{pH}$, but did increase antimicrobial action against the biofilm of Enterococcus faecalis (de Freitas et al., 2017).The authors suggested that the use of NSAIDs (such as diclofenac) in tandem with $\mathrm{CH}$ paste would be a possible alternative to antibiotic use.

\section{The impact of diclofenac on lotic biofilms}

NSAIDs such as diclofenac have potential toxicity, and their presence in the environment may have adverse impacts on fauna and microbiota. These drugs can be found in significant amounts in aquatic environments in many parts of the world (Lonappan et al., 2016).Biofilms are considered important indicators of both the toxicity and degradation processes of chemical pollutants in aquatic environments, as these represent sites in which such chemicals interact with a diverse and complex microbiota (Sabater et al., 2007).In this way, some studies have demonstrated the effect of diclofenac on lotic biofilms.

Paje et al., (2002) used river water as the inoculum and sole source of nutrient supply for the growth of environmental biofilms with a wide variety of bacteria, cyanobacteria, and algae.The biofilm development of the control experiment was compared to that of diclofenac-treated reactors. After four weeks of exposure to $100 \mu \mathrm{g} / \mathrm{L}$ diclofenac, the older biofilms - grown for 11 weeks before exposure to diclofenac - lost up to $70 \%$ of their initial biomass.

On the other hand, bacteria from the Cytophaga-Flavobacterium group survived to exposure to diclofenac and were able to degrade more than $90 \%$ of the original compound within five days of its application, demonstrating the ability of some microorganisms to adapt to this compound. Additionally, the authors reported that diclofenac promoted a selective effect, reducing the proportion of the population of Gram-positive bacteria. About $68 \%$ of the colonies isolated from the untreated biofilms were Gram-positive while almost the same proportion of isolates from the diclofenactreated reactors was Gram-negative bacteria. 
Table.1 Diclofenac inhibitory activity against Gram negative bacteria and the methods employed

\begin{tabular}{|c|c|c|c|c|}
\hline Bacteria & Source & $\mathrm{MIC}(\mu \mathrm{g} / \mathrm{mL})$ & Method & Reference \\
\hline \multirow{6}{*}{ Escherichia coli } & Clinical & $0.25-1024$ [256] & Agar dilution & Ahmed et al., (2017) \\
\hline & Clinical & $2-100$ & Broth dilution & Mazumdar et al., (2006) \\
\hline & ATCC 25922 & 10 & Broth dilution & Mazumdaret al., (2006) \\
\hline & Clinical & $50->1000$ & Agar dilution & Duttaet al., (2007a) \\
\hline & K12 C600 & 50 & Agar dilution & Duttaet al., (2007a) \\
\hline & Clinical & 2500 & Broth dilution & AL-Janabi et al., (2009) \\
\hline \multirow[t]{2}{*}{ Klebsiellapneumoniae } & ATCC 10031 & 1024 & Agar dilution & Ahmed et al., (2017) \\
\hline & ATCC 10031 & 173.7 & AWD with MIC* & Mohsen et al., (2015) \\
\hline \multirow[t]{2}{*}{ Klebsiellaspp } & Clinical & $2-1024[256]$ & Agar dilution & Ahmed et al., (2017) \\
\hline & Clinical & $\leq 200->100$ & Agar dilution & Dutta et al., (2007a) \\
\hline \multirow{2}{*}{ Proteusmirabilis } & Clinical & 2 & Broth dilution & Hegazy (2016) \\
\hline & Clinical & 1769.5 & AWD with MIC* & Mohsen et al., (2015) \\
\hline Proteusspp & Clinical & $2-64[64]$ & Agar dilution & Ahmed et al., (2017) \\
\hline Salmonella spp. & Clínical & $50->1000$ & Agar dilution & Duttaet al., (2007a) \\
\hline S. Typhimurium & NCTC 11 & 100 & Agar dilution & Annaduraiet al., (2002) \\
\hline \multirow[t]{2}{*}{ S. Typhi } & NCTC 74 & 50 & Agar dilution & Annadurai et al., (2002) \\
\hline & Clinical & 2500 & Broth dilution & AL-Janabi et al (2009) \\
\hline Shigella spp. & Clínical & $50->100$ & Agar dilution & Duttaet al., (2007a) \\
\hline \multirow[t]{2}{*}{ S. dysenteriae } & 3 NCTC 102/65 & 200 & Agar dilution & Annaduraiet al., (2002) \\
\hline & 4a NCTC 515/63 & 100 & Agar dilution & Annadurai et al., (2002) \\
\hline Enterobacter cloacae & Clinical & 2500 & Broth dilution & AL-Janabi et al., (2009) \\
\hline E. aerogenes & Clinical & 2500 & Broth dilution & AL-Janabiet al., (2009) \\
\hline Vibriocholerae & Clínical & $50-\geq 1000$ & Agar dilution & Duttaet al., (2007a) \\
\hline \multirow{4}{*}{ Pseudomonasaeruginosa } & ATCC 1045 & 1024 & Agar dilution & Ahmed et al., (2017) \\
\hline & Clínical & 3125 & Agar dilution & Abbas et al., (2012) \\
\hline & Clínical & 2.000 & Broth dilution & Abbas (2015) \\
\hline & ATCC 1014 & 1675.7 & AWD with MIC* & Mohsen et al., (2015) \\
\hline \multirow[t]{2}{*}{ Pseudomonasspp. } & Clínical & $4-256[256]$ & Agar dilution & Ahmed et al., (2017) \\
\hline & & $\begin{array}{l}\text { Concentration / Z of } \\
\text { Inhibition (mm) }\end{array}$ & & \\
\hline \multirow[t]{2}{*}{ E. coli } & ATCC 9637 & $2500 / 14$ & AWD & Umaru et al., (2009) \\
\hline & MTCC 443 & $25-100 / 24-25$ & AWD & Padma and Yalavarthy (2015) \\
\hline S. Typhi & ATCC 13709 & $2500 / 13$ & AWD & Umaru et al., (2009) \\
\hline \multirow[t]{2}{*}{ P. aeruginosa } & ATCC 27853 & $2500 / 8$ & AWD & Umaru et al., (2009) \\
\hline & MTCC 424 & $25-100 / 24-26$ & AWD & Padma and Yalavarthy (2015) \\
\hline S. Typhi & MTCC 98 & $25-100 / 22-23$ & AWD & Padma and Yalavarthy (2015) \\
\hline
\end{tabular}

MIC: Minimum inhibitory concentrations; [ ]: MIC $_{90}$; AWD: Agar Well Diffusion; *: MIC was calculated by plotting the natural logarithm of the concentration of each dilution against the square of zones of inhibition 
Table.2 Diclofenac inhibitory activity against Gram positive and mycobacteria and the methods employed

\begin{tabular}{|c|c|c|c|c|}
\hline Bacteria & Source & $\operatorname{MIC}(\mu \mathrm{g} / \mathrm{mL})$ & Method & Reference \\
\hline \multirow{12}{*}{ Staphylococcus aureus } & NCTC 6571 & 50 & Agar dilution & Duttaet al., (2007a) \\
\hline & NCTC 6571 & 50 & Broth dilution & Dastidaret al., (2000) \\
\hline & Clinical & $50->1000$ & Agar dilution & Duttaet al., (2007a) \\
\hline & ATCC 25923 & 1250 & Broth dilution & Chan et al., (2017) \\
\hline & ATCC 33591 & 312 & Broth dilution & Chan et al., (2017) \\
\hline & Clinical & $312-2500$ & Broth dilution & Chan et al., (2017) \\
\hline & ATCC 6538 & $4.7(\mathrm{mM})$ & Broth dilution & El-Baky and El-Gendy (2016) \\
\hline & Clinical & $2.35-4.7(\mathrm{mM})$ & Broth dilution & El-Baky and El-Gendy (2016) \\
\hline & Clinical & $8-1024[256]$ & Agar dilution & Ahmed et al., (2017) \\
\hline & ATCC 6538 & 1465 & AWD* & Mohsen et al., (2015) \\
\hline & Clinical & 615 & Broth dilution & AL-Janabi et al., (2009) \\
\hline & ATCC 25923 & {$[250]$} & Broth dilution & Alqahtani et al., (2018) \\
\hline CoNS & Clinical & $0.5-1024[256]$ & Agar dilution & Ahmed et al., (2017) \\
\hline S. epidermidis & Clinical & 250 & Broth dilution & Perilli et al., (2000) \\
\hline \multirow[t]{2}{*}{ Enterococcus faecalis } & Clinical & $8-256[256]$ & Agar dilution & Ahmed et al., (2017) \\
\hline & ATCC 29212 & 50 & Broth dilution & Salem-Milani et al., (2013) \\
\hline Streptococcus spp. & Clinical & $1-256[256]$ & Agar dilution & Ahmed et al., (2017) \\
\hline Bacillus spp & Clincal & $0.5-2[2]$ & Agar dilution & Ahmed et al., (2017) \\
\hline B. pumilus & NCTC 8241 & 50 & Agar dilution & Annadurai et al., (2002) \\
\hline \multirow[t]{2}{*}{ B. subtilis } & Clinical & 0.315 & Broth dilution & AL-Janabi et al., (2009) \\
\hline & ATCC 23857 & {$[50]$} & Broth dilution & Alqahtani et al., (2018) \\
\hline \multirow[t]{2}{*}{ Listeria monocytogenes } & ATCC 51774 and others & {$[50]$} & Agar dilution & Duttaet al., 2008a) \\
\hline & ATCC 51774 and others & {$[50]$} & Broth dilution & Duttaet al., (2009) \\
\hline Mycobacterium tuberculosis & Standard and clinical & $10-2510$ & Agar dilution & Dutta et al., (2007b) \\
\hline \multirow[t]{2}{*}{ Mycobacterium spp. } & Clinical & $10-25$ & Broth dilution & Dutta et al., (2004) \\
\hline & & $\begin{array}{l}\text { Concentration / } \mathrm{Z} \text { of } \\
\text { Inhibition }(\mathrm{mm})\end{array}$ & & \\
\hline B. subtilis & MTCC 441 & $25-100 / 18-19 \mathrm{~mm}$ & AWD & Padma and Yalavarthy (2015) \\
\hline S. aureus & MTCC 96 & $50-100 / 16-21 \mathrm{~mm}$ & AWD & Padma and Yalavarthy (2015) \\
\hline
\end{tabular}

MIC: Minimum inhibitory concentrations; [ ]: $\mathrm{MIC}_{90}$; CoNS: Coagulase negative Staphylococci; AWD = Agar Well Diffusion; *: MIC was calculated by plotting the natural logarithm of the concentration of each dilution against the square of zones of inhibition

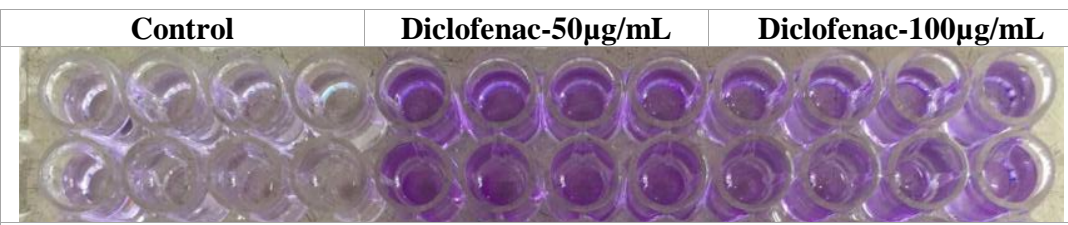

Figure 1. Induction of biofilm by diclofenac in two clinical strains of $S$. aureus (work in progress) 
Lawrence et al., (2007) investigated the impact of 10 and $100 \mu \mathrm{g} / \mathrm{L}$ diclofenac on river biofilm communities grown as model systems in rotary annular reactors. However, in contrast to the results obtained by Paje et al., (2002), these authors observed that $100 \mu \mathrm{g}$ / L of the drug did not reduce bacterial biomass; instead, the direct counts indicated increased bacteria numbers, along with an increase in the thickness of the biofilms. Diclofenac also produced significant effects on the nature of the bacterial community compared to both the control and communities of the river biofilm treated only with nutrients.

\section{Other effects of diclofenac}

In addition to affecting biofilm formation, NSAIDs may influence the expression of other factors of bacterial virulence. Subinhibitory concentrations of diclofenac significantly inhibited swarming and swimming motilities of $P$. mirabilis isolated from a diabetic foot, indicating that the spread of infection could be affected by this NSAID. Noticeable decreases in or inhibition of protease, hemolytic and urease activities were also observed (Hegazy, 2016).

In a similar study with Pseudomonas, Abbas (2015) showed that subinhibitory concentrations of diclofenac equally decreased twitching and swimming motility, affected protease and hemolytic activities, and induced a significant decrease in the production of pyocyanin and pioverdine.Decreases in the production of regulated quorum sensing virulence factors (elastase and pyocyanin) and in swarming motility were also previously reported as effects of diclofenac in $P$. aeruginosa (Ulusoy and Bosgelmez-Tinaz, 2013).

It is concluded that, due to the rapid increase and global spread of antimicrobial resistance over the last decades, there are currently few effective conventional therapeutic options for the treatment of certain infections involving multiresistant pathogens. The problem is aggravated in biofilm-associated infections, which, when present, create a barrier that prevents antimicrobial access.

The pharmaceutical industry's difficulties in responding to antimicrobial resistance have made the establishment of alternative approaches to the control of such infections even more urgent. In this sense, the use of "non-antibiotic" drugs represents an interesting approach, either for single use or as adjuvant to conventional antibiotics.However, some limitations emerging from the studies on diclofenac must be taken into account.

The MICs reported in the different investigations for this drug show great variation, which may be the result of methodological factors, such as the type of solvent used in the dissolution of the drug (for example, distilled water instead of methanol or DMSO), culture media and techniques used by the authors.

Further clinical studies are required, as well as a better understanding of the effect of subinhibitory concentrations of this NSAID on bacterial biofilm formation.

An obstacle to the current use of diclofenac as an alternative to the conventional antibiotics, or as an adjuvant drug to the antibiotics, is that, with a few exceptions, the MICs obtained in in vitro tests are above those achieved in serum. However, the fact that diclofenac penetrates efficiently into inflamed tissues and synovial fluid - where high concentrations are maintained compared to plasma concentrations - should be taken into account. High concentrations of the drug can also be achieved with topical therapy. 


\section{References}

Abbas, H.A. (2015). Inhibition of virulence factors of Pseudomonas aeruginosa by Diclofenac Sodium. Roum. Arch.Microbiol.Immunol. 74(3-4):7985.

Abbas, H.A., Serry, F.M., and EL-Masry E.M. (2012).Combating Pseudomonas aeruginosa biofilms by potential biofilm inhibitors. Asian J. Res. Pharm. Sci. 2 (2): 66-72.

Ahmed, E.F., El-Baky, R.M., Ahmed, A.B.,Waly, N.G., and Gad G.F. (2017). Antibacterial Activity of Some Non-steroidal Anti-inflammatory Drugs against Bacteria Causing Urinary Tract Infection. Am. J. Epidemiol. Infect. Dis. 5: 66-73.

AL-Janabi, A.S.(2009).Comparison of disc diffusion assay with spectrophotometer technique for antibacterial activity of diclofenac sodium, indomethacin and mefenamic acid. Asian J. Pharm. 3: 148-52.

Alqahtani, F.Y.A.,Aleanizy, F.S.A., El Tahir, E.,Alquadeib, B.T.,Alsarra I.A.,Alanazi, J.S., and Abdelhady, H.G. (2018). Preparation, characterization, and antibacterial activity of diclofenac-loaded chitosan nanoparticles. Saudi Pharmaceutical Journal.https://doi.org/10.1016/j.jsps.2 018.08.001

Annadurai, S., Basu, S., Ray, S., Dastidar, S.G., and Chakrabarty A.N. (1998). Antibacterial activity of the antiinflammatory agent diclofenac sodium. Indian J. of Exptl. Biology 36 (1): 86-90.

Annadurai, S., Guha-Thakurta A., S.A.B., Dastidar S.G., Ray R., and Chakrabarty AN. (2002). Experimental studies on synergism between aminoglycosides and the antimicrobial antiinflammatory agent diclofenac sodium. J. Chemoth. 14(1): 47-53.

Baldiris, R., Teherán, V., Vivas-Reyes, R., Montes, A., and Arzuza O. (2016). Anti-biofilm activity of ibuprofen and diclofenac against some biofilm producing Escherichia coli and Klebsiella pneumoniae uro pathogens. Afr. J.Microbiol. Res. 10(40): 16751684.

Chan, E.W.L., Yee, Z.Y., Raja, I., and Yap, J.K.Y. (2017).Synergistic effect of non-steroidal anti-inflammatory drugs (NSAIDs) on antibacterial activity of cefuroxime and chloramphenicol against methicillin-resistant Staphylococcus aureus. J. Glob. Antimicrob. Resist. 10:70-4.

Cramton, S.E., Gerke, C., Schnell, N.F., Nichols, W.W., and Cotz F. (1999).The intercellular adhesion (ica) locus is present in Staphylococcus aureus and is required for biofilm formation. Infect. Immun.67(10): 5427-5433.

Dastidar, S., Jairaj, J., Mookerjee, M., and Chakrabarty A. (1996).Studies on antimicrobial effect of the antihistaminic phenothiazine trimeprazine tartrate. Acta Microbiologicae tImmunologica Hungarica. 44: 241-247.

Dastidar, S.G., Ganguly, K., Chaudhuri, K., and Chakrabarty, AN. (2000).The antibacterial action of diclofenac shown by inhibition of DNA synthesis. Int. J.Antimicrob.Agents.14:249-251.

deFreitas, R.P., Greatti, V.R., Alcalde, M.P., Cavenago, B.C., Vivan, R.R., Duarte, M.A.H., and Weckwerth, P.H. (2017). Effect of the association of nonsteroidal anti-inflammatory and antibiotic drugs on antibiofilm activity and $\mathrm{pH}$ of calcium hydroxide pastes. 
J.Endod. 43:131-134.

Dinarello, C.A. (2010). Anti-inflammatory agents: Present and future. Cell. 140: 935-950.

Dutta, N.K, Annadurai S., Mazumdar, K.,Dastidar, S.G., Kristiansen, J.E., Molnar, J., Martins, M., Amaral, L. (2007a). Potential management of resistant microbial infections with a novel non-antibiotic: the antiinflammatory drug diclofenac sodium. Int. J. Antimicrob. Agents. 30:242-9.

Dutta, N.K., Dastidar, S.G., Kumar, A., Mazumdar, K., Ray, R., and Chakrabarty, A.N. (2004b). Antimycobacterial activity of the antiinflammatory agent diclofenac sodium, and its synergism with streptomycin. Braz. J. Microbiol. 35:316-323.

Dutta, N.K., Kumar, K.A., Mazumdar, K., and Dastidar, S.G. (2004a). In vitro and in vivo antimycobacterial activity of antiinflammatory drug, diclofenac sodium. Indian J. Exp.Biol. 42(9):922-927.

Dutta, N.K., Mazumdar, K., and Park, J.H. (2009). In vitro synergistic effect of gentamicin with the anti-inflammatory agent diclofenac against Listeria monocytogenes. Lett. Appl. Microbiol., 48(6):783-785.

Dutta, N.K., Mazumdar, K., Baek, M.W., Kim, DJ, Na, Y.R., Park, S.H., Lee, H.K., Lee, B.H., and Park, J.H.(2008a). In vitro efficacy of diclofenac against Listeria monocytogenes. Eur. J.Clin.Microbiol. Infect. Dis. 27 (4):315-319.

Dutta, N.K., Mazumdar, K., Dastidar, S.G., and Park, J.H. (2007b.)Activity of diclofenac used alone and in combination with streptomycin against Mycobacterium tuberculosis in mice. Int. J. Antimicrob. Agents. 30 (4): 336-40
Dutta, N.K., Mazumdar, K., Seok, S.H., and Park, J.H. (2008b). The antiinflammatory drug Diclofenac retains anti-listerial activity in vivo. Lett. Appl. Microbiol. 47:106-111.

El-Baky, R.M.A., and El-Gendy, S.G. (2016).Effect of non-steroidal antiinflammatory drugs and dexamethazone on the biofilm formation and expression of some adhesion-related genes of Candida albicans and Staphylococcus aureus. Afr. J. Microbiol. Res.10:694-707.

Hegazy, W.A.H. (2016). Diclofenac inhibits virulence of Proteus mirabilis isolated from diabetic foot ulcer. Afr. J.Microbiol. Res.10:733-743.

Kristiansen, J.E. (1979). Experiments to illustrate the effect of chlorpromazine on the permeability of the bacterial cell wall. Acta Pathol. Microbiol. Scand. B. 87: 317-9.

Kristiansen, J.E. (1992). The antimicrobial activity of non-antibiotics. Report from a congress on the antimicrobial effect of drugs other than antibiotics on bacteria, viruses, protozoa, and other organisms. APMIS Suppl. 30: 714.

Lawrence, J.R, Swerhone, G.D., Topp, E., Korber, D.R, Neu, T.R., and Wassenaar L. (2007). Structural and functional responses of river biof.ilm communities to the nonsteroidal antiinflammatory diclofenac. Environ. Toxicol. Chem. 26: 573-582.

Lonappan, L., Brar, S.K., Das, R.K., Verma, M., and Surampalli, R.Y. (2016). Diclofenac and its transformation products: environmental occurrence and toxicity - a review. Environ. Int. 96:127-138.

Mazumdar, K., Dastidar, S.G., Park, J.H., and Dutta N.K. (2009). The antiinflammatory non-antibiotic helper compound diclofenac: an antibacterial 
drug target. Eur J

ClinMicrobiol.Infect.Dis. 28:881-891.

Mazumdar, K., Dutta, N.K., Dastidar, S.G., Motohashi, N., and Shirataki, Y. (2006). Diclofenac in the management of $E$. coli urinary tract infections. In Vivo.20:613-619.

Mohsen, A., Gomaa, A., Mohamed, F., Ragab, R., Eid, M., Ahmed, A-H., Khalaf, A., Kamal, M., Mokhtar, S., Mohamed, H., Salah, I., Abbas, R., Ali, S., and El-Baky, R.M. (2015).Antibacterial, Anti-biofilm Activity of Some Non-steroidal AntiInflammatory Drugs and N-acetyl Cysteine against Some Biofilm Producing Uropathogens. Am. J. Epidemiol. Infect. Dis. 3(1):1-9.

Oprea, V., and Moga, D. (2015). Why Should Be Removed Chronic Infected Abdominal Synthetic Meshes? A Review.Glob. J. Surg. 3(2): 17-23.

Otto, M. (2013). Staphylococcal Infections: Mechanisms of Biofilm Maturation and Detachment as Critical Determinants of Pathogenicity. Annu. Rev. Med. 64:175-88.

Padma, R., and Yalavarthy, P.D. (2015). Screening of Diclofenac for Antibacterial activity against Pathogenic Microorganisms. Int. J. Adv. Pharm. Biol. Chem. 4(3):554558.

Paje, M.L.F., Kuhlicke, U., Winkler, M., andNeu, T.R. (2002).Inhibition of lotic biofilms by diclofenac. Appl. Microbiol. Biotechnol. 59: 488-492.

Perilli, R.,Marziano, M.L, Formisano, G., Caiazza, S., Scorcia, G., and Baldassarri, L. (2000). Alteration of organized structure of biofilm formed by Staphylococcus epidermidis on soft contact lenses. J. Biomed. Mater.Res. 49(1): 53-5.

Reśliński, A., Dąbrowiecki, S., and Głowacka, K. (2015). The impact of diclofenac and ibuprofen on biofilm formation on the surface of polypropylene mesh.Hernia19:179185.

Riordan, J.T., Dupre, J.M., Cantore-Matyi, S.A., Kumar-Singh, A., Song, Y., Zaman, S., Horan, S., Helal, N.S., Nagarajan, V., Elasri, M.O., Wilkinson, B.J., and Gustafson, J.E. (2011). Alterations in the transcriptome and antibiotic susceptibility of Staphylococcus aureus grown in the presence of diclofenac. Ann. Clin. Microbiol. Antimicrob. 10:30. doi:10.1186/14760711-10-30.

Sabater, S., Guasch, H., Ricart, M., Romaní, A., Vidal, G., Klünder, C., and Schmitt-Jansen, M. (2007). Monitoring the effect of chemicals on biological communities. The biofilm as an interface. Anal.Bioanal. Chem. 387:1425-1434.

Salem-Milani, A., Balaei-Gajan, E., Rahimi, S., Moosavi,Z., AbdollahiA, ZakeriMilani, P. and Bolourian,M. (2013). Antibacterial effect of diclofenac sodium on Enterococcus faecalis. J. Dent. (Tehran) 10:16-22.

Shah, P.N., Marshall-Batty, K.R., Smolen, J.A., Tagaev, J.A., Chen, Q., Rodesney, C.A., Le, H.H., Gordon, V.D., Greenberg, D.E., and Cannon, C.L. (2018). Antimicrobial Activity of Ibuprofen against Cystic FibrosisAssociated Gram-Negative Pathogens. Antimicrob. Agents. Chemother. 62(3): e01574-17.

Shepherd, W.F., Fsadni, M.G., and Raj, P.S. (1998). A clinical evaluation of diclofenac-gentamicin combination eye drops in the control of inflammation after cataract surgery. Diclofenac-Gentamicin versus Gentamicin Study Group. Ocul. Immunol. Inflamm. 6(1):13-18. 
Ulusoy, S., and Bosgelmez-Tinaz, G.(2013). Nonsterodial antiinflammatory drugs reduce the production of quorum sensing regulated virulence factors and swarming motility in human pathogen Pseudomonas aeruginosa. Drug Res. (Stuttg) 63:409-413.

Umaru, T., Nwamba, C.O., Kolo, I., and Nwodo, U.U. (2009). Antimicrobial activity of non-steroidal antiinflammatory drugs with respect to immunological response: Diclofenac sodium as a case study. Afr. J. Biotechnol. 8 (25): 7332-7339.

Waters, C.M., and Bassler, B.L.(2005). Quorum sensing: Cell-to-Cell
Communication in Bacteria. Annu. Rev. Cell. Dev. Biol. 21:319-346.

Yin, Z., Wang, Y., Whittell, L.R., Jergic, S., Liu, M., Harry, E., Dixon, N.E., Kelso, M.J., Beck, J.L., and Oakley, A.J. (2014). DNA replication is the target for the antibacterial effects of nonsteroidal anti-inflammatory drugs. Chem. Biol. 21:481-487.

Zimmermann, P., and Curtis N. (2017).Antimicrobial effects of antipyretics. Antimicrob. Agents Chemother. 61:e02268-2316. https://doi.org/10.1128/AAC.02268-16.

\section{How to cite this article:}

Agostinho Alves de Lima e Silva and Priscila Martins Silva. 2018. Non-Antibiotic Compounds: The Activity of the Nsaid Diclofenac on Bacteria- A Review. Int.J.Curr.Microbiol.App.Sci. 7(12): 340-351. doi: https://doi.org/10.20546/ijcmas.2018.712.042 